\section{Improved management of patients with osteoporosis}

To the Editor: We commend Professor Davey's pleas ${ }^{1}$ for greater awareness and improved management of patients suffering from osteoporosis or osteopenia and those with fragility fractures, particularly the elderly.

We contend that this disease is not optimally managed locally and is often still regarded as an inevitable part of the ageing process, not amenable to treatment. The facts that $20 \%$ of hip fracture victims die within one year of the event and that less than $50 \%$ are capable of leading an independent life are often ignored. Moreover, the fact that fracture risk can be halved when lifestyle measures and appropriate bone-active drugs are employed also seems to go unrecognised. The National Osteoporosis Foundation of South Africa (NOFSA) published a guideline on the diagnosis and management of osteoporosis in 2010 that is available in print and also freely available on our website, either as a full guideline or an executive summary. ${ }^{2}$

Unfortunately, osteoporosis medication is still not freely available to sufferers from this common disease, which affects one out of every four postmenopausal women and $20 \%$ of elderly men. The essential drugs list (EDL) published in June $2012^{3}$ suggests that only patients with a bone mineral density (BMD) T-score of -2.5 standard deviation plus a fracture should be considered for treatment with bone-active medication. This is analogous to recommending that you should first have a stroke before your hypertension is eligible for treatment, or have a myocardial infarction before your dyslipidaemia is deserving of a statin! Clearly these EDL recommendations are embarrassingly out of touch with reality. There also appear to be regional differences in the availability of bone-active drugs in the public sector which is particularly problematic in the Western Cape, where NOFSA is frequently approached by patients and doctors unable to obtain justifiable osteoporosis treatment from a clinic or hospital. Moreover, unlike other provinces where access to modern intravenous bisphosphonates, strontium ranelate and even teriparatide can be obtained with or even without motivation, patients in the Western Cape are 'fortunate' when daily generic alendronate is made available the efficacy and safety of which has been questioned. ${ }^{4-8}$

Access to osteoporosis medication is not only problematic in the public sector, however, and private patients, often the elderly and less wealthy, have similar problems. It is illogical that the test to diagnose the disease (dual-energy X-ray absorptiometry measurement of BMD) and the treatment of its complications (e.g hip replacement) are readily reimbursed, yet its effective prevention is not. This is reminiscent of HIV/AIDS, the complications of which were treated for many years in this country before effective treatment of the disease itself was finally accepted and implemented. Unless one is on the very top tier of a medical aid scheme, funders do not usually reimburse osteoporosis medication. Since osteoporosis does not feature on the so-called Prescribed Minimum Benefits (PMB) list, medical aid schemes either refuse to pay or draw up their own arbitrary funding criteria and financially cap the reimbursement of osteoporosis treatment. This does not happen with other chronic non-communicable diseases. Patients are requested to make co-payments and the doctor's ability to prescribe a particular drug is often severely limited, regardless of motivation and good scientific evidence of benefit.

Several new osteoporosis drugs, ranging from specific monoclonal antibodies against RANKL (e.g. denosumab, already launched elsewhere $)^{9}$ to inhibitors of cathepsin $\mathrm{K}$ (e.g. odanacatib) ${ }^{10}$ to potent bone formation stimulating agents (e.g. anti-sclerostin antibodies) ${ }^{11}$ will hit our markets in the foreseeable future, resulting in what Professor Davey terms '... widening the therapeutic horizons'. Although it might be a while before we have access to these exciting agents, it is NOFSA's firm belief that every effort should be made to provide sufferers from this crippling disease rightful access to available effective therapy, in both the private and the public sectors.

Stephen Hough (Chair), Sue Brown, Bilkish Cassim, Mike Davey, Tobie de Villiers, Graham Ellis, Stan Lipschitz, Mac Lukhele, John Pettifor

for the National Osteoporosis Foundation of South Africa (NOFSA)

PO Box 481

Bellville, 7535

fsh@sun.ac.za

Davey DA. Osteoporosis, osteopenia and fracture risk: Widening the therapeutic horizons. S Afr Med 2012;102(5):285-288

2. Hough FS, Ascott-Evans B, Brown SL, Cassim B, de Villiers TJ, Lipschitz S, Pettifor JM, Sonnendecker EWW for the National Osteoporosis foundation of South Africa (NOFSA). NOFSA Guideline for the Diagnosis and Management of Osteoporosis. Journal of Endocrinology Metabolism and Diabetes of Diagnosis and Management of Osteoporosis. Journal of Endocrinology Metabolism and Diabetes of
South Africa 2010;15(3,suppl 1):1-188. http//www.osteoporosis.org.za (accessed 8 October 2012).

3. Standard Treatment Guidelines and Essential Medicines List for South Africa. 3rd ed. 2012. http:// www.kznhealth.gov.za/pharmacy/edladult_2012.pdf (accessed 8 October 2012).

www.kznhealth.gov.Za/pharmacy/edladult_2012.pdf (accessed 8 October 2012).
Hough FS. NOFSA statement on generic bisphosphonates. S Afr Med J 2006;96:758-760. 4. Hough FS. NOFSA statement on generic bisphosphonates. S Afr Med I 2006;96:758-760.
5. Ringe JD, Moller G. Differences in persistence, safety and efficacy of generic and original branded once weekly bisphosphonates in patients with postmenopausal osteoporosis: 1-year results and retrospective 6940-5]

6. Ström $\mathrm{O}$, Landfeldt E. The association between automatic generic substitution and treatment with oral bisphosphonates. Osteoporos Int 2012;23(8):2201-2209. [http://dx.doi.org/10.1007/s00198-011850-4]

Sheehy O, Kindundu CM, Barbeau M, LeLorier J. Differences in persistence among different weekly ral bisphosphonate medications. Osteoporos Int 2009;20(8):1369-1376. [http://dx.doi.org/10.1007/ 00198-008-0795-8]

8. Kanis JA, Reginster JY, Kaufman JM, et al. A reappraisal of generic bisphosphonates in osteoporosis. Osteoporos Int 2012,23(1):213-221. [http://4x.doi.ong/10.1007/s00198-011-1796-6]

Cummings SR, San Martin J, McClung MR et al. for the FREEDOM trial. Denosumab for prevention of fractures in postmenopausal women with osteoporosis. N Engl J Med 2009;361:756-765. [http:// x.doi.org/10.1056/NEJMoa0809493]

10. Boonen S, Rosenberg E, Claessens F, et al. Inhibition of cathepsin K for treatment of osteoporosis. Curr Osteoporosis Rep 2012;10(1):73-79. [http://dx.doi.org/10.1007/s11914-011-0085-9]

11. Ke HZ, Richards WG, Ominski MS. Sclerostin and Dickkopf -1 as therapeutic targets in bone disease. Endocr Rev 2012;33(5):747-783. [http://dx.doi.org/10.1210/er.2011-1060]

S Afr Med J 2012;102(11):815. DOI:10.7196/SAMJ.6317

\section{Can the re-engineering of $\mathrm{PHC}$ and/ or the introduction of community paediatricians be the solution?}

To the Editor: The recent article about the new paediatric sub-specialty to improve child health in South Africa quotes grim child health statistics to illustrate the need to look for new strategies to improve child health. ${ }^{1}$ Can the re-engineering of primary healthcare (PHC) and/or the introduction of community paediatricians be the solution?

I would like to share my experience. We were also confronted with bad child health conditions and statistics, but achieved great improvement in one decade (Table 1)..$^{2-4}$

The improvement in maternal and child health was achieved by the vigorous implementation of PHC in the whole catchment area of the Gelukspan Community Hospital. The factors contributing to this achievement included a change from curative hospitalbased medicine to PHC; a determined effort to reach every child and pregnant woman in the community; comprehensive and integrated approach by the health services as a whole and no fragmentation; building a health team with strong reliance on nurses and allied health workers; and re-allocation of staff and resources to community-based services so that all villages had a clinic or visits by a mobile clinic.

During this time a visit to the hospital by the late Professor John Hansen during his sabbatical had a profound impact on the development of the services as a result of his enthusiasm and encouragement. However, the work was done by the PHC team 


\section{CORRESPONDENCE}

Table 1. Health status indicators, Gelukspan Health Ward 1978 - 1989

\begin{tabular}{llll}
\hline Indicator & $\mathbf{1 9 7 8}$ & $\mathbf{1 9 8 5}$ & $\mathbf{1 9 8 9}$ \\
\hline No. of children $<5$ years & 9000 & 13500 & \\
Perinatal mortality rate & $60 / 1000$ & $78 / 1000$ & $39 / 1000$ \\
Infant mortality rate & $>200 / 1000$ & $41 / 1000$ & $24 / 1000$ \\
$<5$ mortality rate & $105 / 1000$ & $17 / 1000$ & $6 / 1000$ \\
No. of paediatric deaths in & $144^{*}$ & 63 & 33 \\
hospital & & & \\
No. of visits to UFC/child & $<1 /$ year & $7 /$ year & \\
Total No. of visits to UFC & 3000 & 95000 & 76709 \\
Home deliveries & $75 \%$ & $29 \%$ & $15 \%$ \\
ANC visits & 2077 & 15375 & 19679 \\
Supervised deliveries & 684 & 2554 & 2981 \\
Maternal mortality rate & $?$ & $180 / 100000$ & $50 / 100000$ \\
Family planning visits & 1000 & & 17746 \\
Health care worker/ & $1 / 7000$ & $1 / 1000$ & \\
population & & & \\
Doctor/population & $1 / 30000$ & $1 / 10000$ & \\
$\begin{array}{l}\text { Midwife/population } \\
\text { *n 1979. }\end{array}$ & $1 / 12000$ & $1 / 2500$ & \\
UFC= under-5 clinic; ANC = antenatal clinic. & &
\end{tabular}

without any specialist doctors or nurses, and with involvement of the mothers as 'the most important health workers'.

A similar remarkable improvement in maternal and child health recently reported from India was achieved by a nurse-driven programme and strong focus on community involvement. ${ }^{5}$ Maternal mortality decreased by $75 \%$ and infant mortality by nearly $50 \%$ to $43 / 1000$ within a few years.

The potential impact of the re-discovery and implementation of $\mathrm{PHC}$ is considerable, and there is no reason to delay starting. The involvement of (community) paediatricians can contribute to the process, but cannot substitute for a focused approach by the whole health team and the involvement of the community.

\section{Martin Bac}

Department of Family Medicine

University of Pretoria

martin.bac@up.ac.za

12. Swingler G, Hendricks $M$, Hall $D$, et al. Can a new paediatric sub-speciality improve child health in South Africa? S Afr Med J 2012;102:738-739.

13. Bac M. Evaluation of child health services at the Gelukspan Community Hospital, Radithuso, Bophuthatswana, 1976-1084. S Afr Med J 1986;70:277-280.

14. Bac M. Progress towards Health for All in the Gelukspan Health Ward - 1985. MD thesis, Medical University of Southern Africa, 1987.

. Van Oord DJ. Fertility transition in a rural African community. MD thesis, Medical University of Southern Africa, 1996.

16. Alehagen SA, Finnström O, Hermansson GV, et al. Nurse-based antenatal and child health care in rural India, implementation and effects - an Indian-Swedish collaboration. Rural and Remote Health 2012;12:2140. http://www.rrh.org.au (accessed 8 October 2012).

S Afr Med J 2012;102(11):815. DOI:10.7196/SAMJ.6368 